\title{
O Webfólio como Procedimento Avaliativo no Processo de Aprendizagens: Sentidos, Significados e Desafios
}

\author{
The Webfolio as Assessment Procedure in the Process \\ of Learning: Senses, Meaning and Challenges
}

\section{JOSEVAL DOS REIS MIRANDA}

Universidade Federal da Paraíba

\begin{abstract}
Resumo: Este artigo tece reflexões sobre a utilização de webfólio ${ }^{1}$ como possibilidade avaliativa desenvolvido na disciplina Avaliação da Aprendizagem no curso de Licenciatura em Ciência da Computação. Tivemos como objetivo geral compreender como o uso de webfólios como procedimento avaliativo pode contribuir no processo de aprendizagens dos estudantes. Como objetivo específico analisar os sentidos, os significados e os desafios do trabalho com o webfólio no processo de aprendizagens. Esse trabalho pautou-se na contribuição teórica de autores que fizeram a tessitura dos eixos Webfólio e Avaliação das aprendizagens. A metodologia foi de cunho qualitativo, por meio de um estudo de caso. Utilizamos a observação, - questionário e a pesquisa bibliográfica. Foram participantes da pesquisa estudantes que estavam matriculados na disciplina Avaliação da Aprendizagem. Os resultados apontam que houve maior espaço para a construção, reflexão e criatividade acerca das aprendizagens pelos estudantes; permitiu o acompanhamento de forma processual das aprendizagens; maior convivência com os recursos tecnológicos e a superação da prática avaliativa excludente.
\end{abstract}

Palavras-chave: Webfólio. Avaliação das aprendizagens. Processo de aprendizagens.

\begin{abstract}
This article reflects on the use of webfólio as an evaluation possibility developed in the discipline Evaluation of Learning in the course of Degree in Computer Science. We had as a general objective to understand how the use of webfolios as assessment procedure may contribute to the students' learning process. As a specific purpose: to analyze the meaning, the meanings and the challenges of working with webfolio in the process of learning. This work was guided in theoretical contribution of authors who made the tessitura of the axes Webfolio and evaluation of learning. The methodology was qualitative in nature, through a case study. We use observation, questionnaire and literature. Participants in the survey were students who were enrolled in the Learning Assessment course. . The results show that: there was more room for the construction, reflection and creativity about learning by students; allowed the monitoring of procedural way of learning; greater familiarity with the technological resources and overcoming the evaluative exclusionary practice.
\end{abstract}

Keywords: Webfolio. Assessment of learning. Learning process.

MIRANDA, Joseval dos Reis. O Webfólio como procedimento avaliativo no processo de aprendizagens: sentidos, significados e desafios. Informática na Educação: teoria \& prática, Porto Alegre, v. 20, n. 2, p. 272-286, mai./ago. 2017.

${ }^{1}$ O Termo Webfólio ou portfólio online serão considerados sinônimos no decorrer do texto, pois ambos significam estar disponível para o acesso imediato a uma página da internet. 


\section{I ntrodução}

O presente texto apresenta aspectos abordados em nossas pesquisas no campo da avaliação das aprendizagens com a utilização do webfólio ou portfólio online e tem como objetivo central compreender como o uso de webfólios, como procedimento, avaliativo pode contribuir para o processo de aprendizagens dos estudantes.

Pensar na utilização do webfólio significa inseri-lo no contexto também das tecnologias da informação e comunicação a serviço das aprendizagens e do processo avaliativo. É indiscutível a necessidade de inovação no processo de ensino e, nesse sentido, a utilização do webfólio possibilita a criação de um ambiente para as aprendizagens que ultrapassa o modelo avaliativo que se utiliza somente da sala de aula.

Tanto o portfólio como o webfólio ou portfólio online são procedimentos de trabalho utilizados no campo da avaliação que coadunam com uma concepção de práticas avaliativas a serviço das aprendizagens.

A organização do trabalho pedagógico por meio do webfólio cria alternativas para a efetivação dos processos de ensino e de aprendizagens permeados pela reflexão, pelo diálogo e compartilhamento do conhecimento, pela autonomia, criatividade e outros elementos que regem o portfólio e se adequam perfeitamente ao webfólio. (VILLAS BOAS, 2004).

A construção deste texto pautou-se em revisão bibliográfica, observação participante, além de questionário semiestruturado, o qual contou com a participação de quinze estudantes regularmente matriculados na disciplina "Avaliação da Aprendizagem", no curso de Licenciatura em Ciência da Computação, no ano letivo de 2015.

Por meio da revisão bibliográfica, foi possível constatar que há várias produções que abordam a temática central do nosso estudo: o webfólio como procedimento avaliativo. Essas produções apontam as múltiplas possibilidades de utilização no webfólio como ferramenta produtiva na organização do trabalho pedagógico e na construção de uma prática avaliativa a serviço das aprendizagens.

No que diz respeito à observação, esta foi realizada durante os dois semestres letivos de 2015 e possibilitou-nos o acompanhamento das construções dos webfólios pelos estudantes, evidenciando aspectos como: a organização, os formatos, a continuidade, a forma como postavam as atividades, as dificuldades encontradas, os momentos de socialização na turma e apresentação final dos webfólios produzidos.

Já o questionário, formulado com oito questões abertas sobre webfólios, foi respondido pelos estudantes durante a construção dos webfólios no ambiente da sala de aula.

Assim, com base nas informações colhidas, buscamos, por meio deste texto, evidenciar a importância do diálogo em torno da avaliação das aprendizagens e do trabalho com o webfólio, considerando os seus sentidos, suas possibilidades e seus desafios, tendo como premissa a construção de um trabalho pedagógico avaliativo inclusivo, reflexivo, crítico e democrático, vislumbrando as aprendizagens de todos e todas. 


\section{Reflexões sobre avaliação das aprendizagens}

O momento atual no cenário educacional tem sido marcado por um contexto de reflexões, indagações, contradições, contraposições, questionamentos, críticas e ressignificação do nosso "fazer pedagógico". Aqui destacamos a importância de que este "fazer" esteja relacionando ao trabalho pedagógico por compreendermos que o "fazer pedagógico" não pode estar apenas na esfera do "fazer" simplesmente técnico, mas também em uma esfera macro, na qual o fazer pedagógico dilui-se no sentir, no vivenciar e no ressignificar, tecendo várias relações entre a própria competência do fazer técnico e desta com outras competências - políticas, sociais, históricas, culturais - tão necessárias ao desenvolvimento do trabalho pedagógico como um todo.

A busca pela qualificação do fazer pedagógico é uma questão complexa e perpassa vários fatores, entre eles a avaliação das aprendizagens, uma vez que não se avalia para atribuir nota, conceito ou menção. Avalia-se para promover a aprendizagem do estudante e, neste sentido, a avaliação e as aprendizagens caminham de mãos dadas (VILLAS BOAS, 2004).

Desta forma, torna-se explícito o quanto a avaliação escolar interfere na construção de práticas pedagógicas mais inclusivas e dessilenciantes, considerando que o nosso olhar avaliativo muitas vezes é periférico, genérico e circunstancial, sendo o resultado de uma formação profissional docente que revela o quanto carecemos romper com o espírito da passividade e do silenciamento que nos foram impregnados pelos padrões impostos durante nossa formação, na qual a avaliação, na maioria das vezes, era vista simplesmente como notas, conceitos, menções, punições e classificações.

A avaliação faz parte da nossa vida em todos os momentos e lugares. Ela é utilizada nas mais diversas situações, por meio dos mais diferentes critérios. Muitas vezes, a avaliação ocorre como forma de testagem, julgamentos ou mesmo como medição de nossas ações para planejamentos o futuro. Entretanto, no contexto educativo a avaliação precisa desenvolver-se sob outra perspectiva, deixando de ser somente um ato normativo e padronizado.

A avaliação praticada na escola pode, portanto, cumprir duas funções, a de classificar o estudante ou a de promover a sua aprendizagem. A primeira tem sido a mais comum, porque tem em vista apenas a atribuição de notas e menções, o que, em geral, contribui para a classificação e exclusão, pois favorece a criação de rótulos e a marginalização dos estudantes. Já a segunda função da avaliação ocorre quando a prática avaliativa se desenvolve sob a perspectiva da emancipação e quando a preocupação (e ocupação) do professor recai no desenvolvimento do estudante como um todo, norteando o seu avanço, e sendo indicadora dos próximos passos durante o processo educativo.

Para Villas Boas (2004), a avaliação existe para que se conheça o que o estudante já compreendeu e o que ainda lhe falta compreender, providenciando os meios necessários para que ele dê continuidade aos estudos. Neste sentido, a avaliação será entendida como fonte principal de informação e referência para a formulação de práticas educativas e, especialmente, como um elemento indissociável do processo educativo. 
Sendo assim, a prática avaliativa, realizada de forma contínua e processual, possibilita definir critérios para planejar e realizar situações que gerem avanços significativos nas aprendizagens, bem como reflexão e tomada de decisões conscientes em relação à própria prática docente, possibilitando ao professor acompanhar as conquistas, as necessidades e as possibilidades dos estudantes ao longo do processo, pois "é função da avaliação a promoção permanente de espaços interativos sem, entretanto, deixar de privilegiar a evolução individual ou de promover ações mediadoras que tenham sentido para o coletivo" (HOFFMANN, 2006, p. 16).

Portanto, mudar a concepção e a prática avaliativa torna-se essencial para a construção de um processo educativo significativo, tanto para os professores como para os estudantes, uma vez que "a avaliação não pode se constituir um processo frio e despersonalizado, pois ela tem que estimular a reflexão do aluno, a compreensão de aspecto que ainda não domina" (GONZÁLEZ REY, 2006, p.39).

Segundo Luckesi (2002), não existe avaliação sem ação, a não ser por exercício de nominalismo, avaliar é ver, julgar e agir, num ciclo ininterrupto. Nessa perspectiva avaliativa, a ampliação do conhecimento deve ser compreendida como construções dinâmicas, por meio da interação da pessoa consigo mesma e com os outros, organizando-se, por meio do sentido subjetivo que vai se desenvolvendo na aprendizagem, pois aprender é uma produção subjetiva, cuja qualidade não está somente na definição das operações lógicas. (GONZÁLEZ REY, 2006).

Desse modo, enxergando a avaliação como ato subjetivo e complexo, percebemos que cabe à prática avaliativa romper as barreiras da padronização e da homogeneidade, as quais buscam descaracterizar o papel do estudante como sujeito do seu processo de aprendizagem, pois ele é “indivíduo concreto portador de personalidade, quem tem como características essenciais e permanentes de sua condição atual, ativo, consciente e intencional" (GONZÁLEZ REY, 2006).

A prática avaliativa, nesse contexto, consubstancia-se na diversidade como característica própria dos seres humanos, a qual é permeada pela complexidade das relações tecidas no cenário social. Vale destacar que complexidade "constitui-se um modo de compreender a realidade no qual é reconhecido o caráter desordenado, contraditório, plural, recursivo, singular, indivisível e histórico que a caracteriza" (MARTí NEZ, 2005, p.4).

Nesse sentido, a sala de aula deve ser concebida como um espaço permeado pelas diversas singularidades, e daí Romanowski (2006) ressalta:

[...] o ambiente da sala de aula é um espaço de vida coletiva, um espaço de relações únicas e originais, semelhantes a um ecossistema para a intensificação da aprendizagem, em que os vínculos dos alunos e dos professores com o conhecimento são acentuados. Professor e aluno transformam-se e transformam o conhecimento em aprendizagem (ROMANOWSKI, 2006, p. 105).

Reconhecer que o cenário, onde se realiza a prática avaliativa, é permeado por toda complexidade significa valorizarmos as diferenças individuais sem jamais perder de vista o contexto interativo entre os vários sujeitos, pois compreende-se que cada estudante constrói significações e sentidos para a sua aprendizagem de maneira própria, diferente e única. 
Nesse contexto são oportunas as palavras de González Rey:

\begin{abstract}
Os sentidos subjetivos constituem verdadeiros sistemas motivacionais que diferentes das teorias mais tradicionais da motivação - permite-nos representar o envolvimento afetivo do sujeito em uma atividade, não apenas pelo seu vínculo concreto nela, mas como produção de sentidos que implica em uma configuração única, sentidos subjetivos, emoções e processos da história individual, como os diferentes momentos atuais da vida de cada sujeito concreto. (GONZÁLEZ REY, 2006, p.34).
\end{abstract}

Em alinhamento ao que compreendemos sobre a avaliação a serviço das aprendizagens Hoffmann (2006) expõe que a prática avaliativa deve estar entrelaçada em três tempos, pois no cotidiano escolar a relação pedagógica precisa ser nutrida de sentido para todos os seus sujeitos em prol de um trabalho educativo com significação. A autora destaca, como primeiro tempo, o tempo da admiração, sendo este um tempo para conhecer o sujeito, por meio do diálogo e de um olhar mais sensível e amplo, a fim de que se possa compreender como o sujeito processa a sua aprendizagem.

Para o segundo tempo da avaliação, Hoffmann (2006) aponta o tempo da reflexão, que se constitui como um tempo para se conhecer o estudante, no que diz respeito à sua trajetória no processo de aprendizagem, tendo em vista não anunciar resultados definitivos ou padronizados.

Já para o terceiro tempo, tempo da reconstrução, é para Hoffmann (2006), o tempo da reconstrução, o tempo de fazer a diferença na prática avaliativa.

Desse modo, acreditamos que uma prática avaliativa com vistas à inclusão, leva em conta o caráter singular do aprender e a compreensão da aprendizagem como prática dialógica, para a qual se deve buscar superar as rasuras dos processos de ensino de aprendizagem centrados somente na memorização e na reprodução do conhecimento, pois a realidade da sala de aula é muito mais dinâmica, ativa e efervescente, devido às várias subjetividades que se fazem presentes nesse contexto.

Corroborando com essas ideias, González Rey (2005, p.37) salienta que o caráter complexo da subjetividade "permite transcender as representações estático-descritivas da psique e mostra a sua representação como sistema que exige a criação de um referente teórico, epistemológico e metodológico distinto".

O autor ainda acrescenta que a subjetividade:

[...] é um sistema em desenvolvimento, no qual as novas produções de sentido constituídos nas atividades do sujeito influenciam o sistema de configurações da personalidade, não de modo imediato, mas de modo mediato nos processos de reconfiguração que acompanham a constante processualidade dos diferentes sistemas de atividades e de relações do sujeito (GONZÁLEZ REY, 2005.p.35).

Não poderíamos deixar de mencionar, mais uma vez, que compreendemos uma prática avaliativa docente permeada por aspectos complexos e subjetivos, pois o próprio ato educativo é, em sua essência, admitido por princípios multifacetados, complexos, relacionais, subjetivos e dialógicos, nos quais o próprio ser humano, por meio da educação, busca o seu desenvolvimento. 
Nesse sentido, Charlot (2000) apud Libâneo (2005) esclarece que o processo da educação:

\begin{abstract}
É o processo por meio do qual um membro da espécie humana inacabado, desprovido dos instintos e das capacidades que lhe permitiriam sobreviver rapidamente sozinho se apropria graças à mediação dos adultos, de um patrimônio humano de saberes, práticas, formas subjetivas, obras. Essa apropriação the permite se tornar, ao mesmo tempo e no mesmo movimento, um ser humano, membro de uma sociedade e de uma comunidade, e um indivíduo singular absolutamente original. A educação é, assim, um triplo processo de humanização, de socialização e de singularização. Esse triplo processo é possível apenas mediante a apropriação de um patrimônio humano. Isso quer dizer que a educação é cultura, em três sentidos que não podem ser dissociados. (CHARLOT, 2000 apud LIBÂNEO, 2005, p.23).
\end{abstract}

Assim sendo, como a educação e o processo de escolarização, pelos quais o ser humano tem acesso às produções e ao conhecimento sistematizado pela humanidade, poderiam, por meio das suas práticas avaliativas, promover a inclusão e não a padronização, a exclusão e a marginalização social? E ainda, qual o papel do professor frente a esta prática avaliativa?

Questionamentos como estes são bastante atuais no seio do debate educacional, pois somos conhecedores do quanto a prática avaliativa classificatória corrobora para aumentar a exclusão e o fracasso escolar, uma vez que, não leva em consideração a complexidade e a subjetividade dos sujeitos e dos espaços que estes ocupam e que se fazem presentes na prática avaliativa. Por isso, a prática docente requer, de cada profissional envolvido no processo educativo, bom senso e responsabilidade, bem como exige atenção às diferenças e, sobretudo, cuidado no ato de avaliar.

Nessa conjuntura, é indispensável ao professor pensar em critérios e instrumentos contextualizados, específicos para cada turma, em cada tempo escolar, possibilitando a definição e o conhecimento dos mecanismos de avaliação por todos os envolvidos, pois a prática avaliativa não pode se dar em um jogo de surpresas ou de mistérios. A esse respeito Hoffmann (2006) explicita que a construção de uma avaliação mediadora é compromisso e responsabilidade de ambas as partes, tanto do professor como do estudante.

A autora menciona o equívoco em que se “discute a avaliação para tentar melhorar a aprendizagem dos alunos, quando se deveria fazer exatamente o inverso: discutir a aprendizagem dos alunos para aperfeiçoar o processo avaliativo e a educação" (HOFFMANN, 2006, p.67). Faz-se necessário, portanto, rever o papel do professor no que diz respeito ao estudante como sujeito do seu próprio processo de aprendizagem, no qual o professor assumirá a postura de facilitador, considerando que aprendizagem dificilmente poderá ocorrer de forma passivo-reprodutiva.

Neste contexto, González Rey ressalta que:

O aluno torna-se sujeito de sua aprendizagem quando é capaz de desenvolver um roteiro diferenciado em relação ao que aprende e a se posicionar crítica e reflexivamente em relação à aprendizagem. [...] A sala de aula tem que se converter em um espaço de diálogo e reflexão. (GONZÁLEZ REY, 2006, p.40).

Assim, buscar a reconstrução ou o redimensionamento das práticas avaliativas perpassa, entre outras questões, pela ressignificação dos aspectos que compõem a subjetividade individual e social na prática avaliativa, pois quando nos referimos às concepções, às 
representações ou aos valores, ali estão aspectos da subjetividade, quer sejam individuais ou sociais. (MARTINEZ, 2003).

\title{
3 Webfólio como possibilidade avaliativa
}

O webfólio ou portfólio online segue os princípios e fundamentos do portfólio construído de forma física. Nesse caso, o webfólio corresponde às produções dos estudantes disponíveis em uma página da web e com a utilização de recursos da internet.

Segundo Nunes e Moreira (2005), o termo portfólio deriva do verbo latino portare (transportar) e do substantivo foglio (folha), designando a pasta que contém desenhos, fotos, textos, pautas de músicas e outras produções dos alunos. Na literatura, é também encontrada a denominação porta-fólio, segundo Villas Boas (2004).

Alves (2006) pontua as várias denominações de acordo com a sua finalidade e o espaço geográfico: porta-fólios, processo-fólio, dossiês e webfólios:

\begin{abstract}
a) Porta-fólio - como é chamado no Canadá, significa uma amostra do dossiê. É o recipiente ou pasta onde se guardam todos os materiais produzidos pelo estudante, cronologicamente.

b) Processo-fólio - visto como instrumento que reflete a crença de que os estudantes aprendem melhor e de uma forma mais integral, a partir de um compromisso com as atividades ocorridas durante um período de tempo significativo que se constrói sobre conexões naturais com os conhecimentos escolares.

c) Webfólios - com os avanços da tecnologia da informação e comunicação, os webfólios podem guardar toda a memória do período escolar desde a educação básica até a educação superior de um estudante, memória que servirá como processo de reconstrução de suas aprendizagens e como elemento de avaliação (ALVES, 2006, p. 104-105).
\end{abstract}

Convém ressaltarmos que, o portfólio era utilizado inicialmente apenas no campo das artes; o artista o utilizava como pasta, na qual guardava seus papéis, desenhos, fotografias e gravuras, sendo o conjunto dos seus trabalhos para apresentar a um cliente ou a grandes públicos, comprovando sua competência profissional.

A exposição de trabalhos de profissionais por meio do portfólio tem como objetivo possibilitar ao destinatário conhecer e contemplar os momentos mais significativos da sua trajetória profissional e, assim, ter uma visão sobre o todo (HERNÁNDEZ, 1998; ESPINOSA e SÁNCHEZ VERA, 2008; SÁNCHEZ, 2005; ALVES, 2006; SHORES \& GRACE, 2001).

No campo educacional, nas últimas décadas, tem sido marcante a presença do portfólio como também do webfólio como procedimentos avaliativos, por se acreditar na necessidade da mudança de concepções e de práticas no campo da avaliação das aprendizagens.

Associado a posturas que visam romper com a centralidade da avaliação pelo professor, com a transmissão e reprodução de conhecimento e a passividade intelectual, o portfólio conquistou espaço como um procedimento avaliativo mais autêntico, dinâmico e reflexivo:

[...] em educação o portfólio adquire outra dimensão, não se limita a mera compilação de trabalhos, sendo que inclui uma narrativa reflexiva que permite a compreensão do processo de ensino e de aprendizagem, segundo o caso, e pode facilitar a avaliação (ESPINOSA; SANCHEZ VERA, 2008, p.21). 
Por caracterizar-se como coletânea de trabalhos produzidos pelos estudantes, evidenciando as aprendizagens, o portfólio e o webfólio consideram as subjetividades e apresentam, ainda, a vantagem de proporcionar aos professores e estudantes uma visão holística da formação, buscando a integração de saberes e o exercício reflexivo, expondo "num primeiro momento, perante si próprio, e num segundo momento, perante aqueles com que colabora no seu processo de formação" (GRILO; MACHADO, 2005, p.35).

Desse modo, diante dos avanços da tecnologia da informação e comunicação, a versão eletrônica do portfólio possibilita um salto qualitativo nos seus formatos, pois podem contar com vídeos, áudios, gráficos, imagens fixas e móveis, entre outros recursos midiáticos. Por isso, segundo Alves (2003),

[...] os webfólios podem guardar toda a memória do período escolar desde a Educação Básica até a Educação Superior de um estudante, que servirá como processo de reconstrução de suas aprendizagens e como elemento de avaliação (ALVES, 2003, p.3).

Embora o webfólio possa ser construído e organizado em forma de blog (contração do termo inglês web $\log =$ diário da rede), este recurso pode não se constituir como um webfólio. Para ser considerado de fato um webfólio ou portfólio online o próprio estudante seleciona, analisa, reflete, organiza, apresenta as suas produções, tomando, assim, as decisões sobre o quê, como, quando e onde inserir ou postar as suas reflexões.

Não poderíamos deixar de mencionar que a construção de webfólios cria a possibilidade de espaços de aprendizagens diversos, pois ultrapassa o modelo escolar vigente, no qual todas as prescrições são dadas quase que exclusivamente em sala de aula e pelo professor. Nessa perspectiva, o estudante, ao criar o seu webfólio, organiza o seu desenvolvimento intelectual, reflete sobre o seu próprio aprendizado, faz uma revisão constante sobre o que já postou e envolve-se ativamente em suas aprendizagens.

Diante de tudo isso, a utilização do webfólio, como ferramenta que auxilia na avaliação e no processo de aprendizagens, se insere na perspectiva de desenvolvimento de uma avaliação formativa. Assim, o foco principal no desenvolvermos do trabalho pedagógico por meio do webfólio e a sua utilização na avaliação, significa buscarmos o desenvolvimento de práticas avaliativas que superem a visão classificatória, excludente e punitiva.

De acordo com Hadji (2001, p. 20), para ser considerada avaliação formativa é preciso que ela seja:

a) Informativa - a partir do momento que ela informa, ela é formativa, que seja instrumentalizada ou não, acidental ou deliberada, quantitativa ou qualitativa;

b) Informa os dois principais atores do processo: o professor e o aluno - o professor seja sempre informado dos efeitos reais do seu trabalho pedagógico e poderá regular a sua ação a partir disso; o aluno poderá tomar consciência das dificuldades que encontra e tornar-se-á capaz, na melhor das hipóteses, de reconhecer e corrigir ele próprio seus erros;

c) Reguladora voltada para o professor e para o aluno - ambos devem poder corrigir a sua ação, modificando, se necessário, seu dispositivo pedagógico, com o objetivo de obter melhores efeitos. A avaliação formativa implica por parte do professor, flexibilidades e vontade de adaptação, de ajuste. Uma avaliação que não é seguida por uma modificação das práticas do professor tem poucas chances de ser formativa! (HADJI, 2001, p.20-21). 
Para Villas Boas (2005), o portfólio possibilita avaliar as capacidades de refletir criticamente, de articular e solucionar problemas, proporcionando ao estudante rever e repensar as suas trajetórias de aprendizagens. Tanto o professor quanto o estudante avaliam todas as atividades realizadas, observando o progresso, o desempenho e os avanços obtidos.

Sendo assim, acreditamos que as características atribuídas ao portfólio podem ser agregadas ao webfólios.

Cano (2005) menciona a influência desse tipo de avaliação para a prática docente:

[...] com a finalidade formativa e de reflexão sobre a ação consideramos que podem contribuir a criar uma nova cultura docente, que na sua vez ajude a desenvolver processos de ensino mais reflexivos e mais consistentes com as exigências da nova sociedade do conhecimento. [...] Serve, então, para revistar periodicamente o programa, reestruturar os conteúdos e atividades, mas também para revistar as próprias metas profissionais (CANO, 2005, p.16).

As reflexões apresentadas até aqui convergem para uma concepção de webfólio como um procedimento que visa à construção de um trabalho coletivo, dialógico e emancipador, proporcionando o exercício do protagonismo de todos os envolvidos no processo. Os autores mencionados no decorrer deste eixo apresentam o webfólio como uma possibilidade de prática avaliativa formativa e contínua que propicia a autoavaliação mediante a reflexão crítica, tanto dos professores quanto dos estudantes.

Desse modo, investigar o trabalho com o webfólio permite ampliar os estudos sobre a temática e também construir junto com os estudantes, possibilidades de avaliação que proporcionem o desenvolvimento da sua capacidade de pensar e de tomar decisões quanto ao seu próprio processo de aprendizagens.

\section{0 que a pesquisa revelou}

A utilização do webfólio como possibilidade avaliativa trouxe resultados e informações importantes. Foi considerado pelos estudantes que participaram da pesquisa que os conteúdos trabalhados adquiriram maior significado, pois ultrapassaram os limites do estudar simplesmente para cumprir as exigências disciplinares. Além disso, possibilitou a realização de pesquisas e a busca pelo aprofundamento nos temas trabalhados, seja por meio de vídeos, imagens ou de outros recursos que foram utilizados no webfólio.

Nesse sentido, sobre o que apreenderam ao construir o webfólio, os estudantes relataram:

Consegui organizar melhor as minhas atividades, desenvolvi a escrita ainda mais, aprimorei o uso e contato com tecnologias, exercitei a minha criatividade (Suzana).

Aprendi a organizar os materiais que utilizamos para construção do nosso aprendizado. E assim fixei melhor a aprendizagem adquirida em pesquisar em outras fontes e outros materiais (Saulo).

Aprendi muito com a construção do meu webfólio. Desenvolvi a leitura, a pesquisa, a escrita, saber selecionar o que postar e também fazer a reflexão sobre aquilo que postei. Foi muito interessante, pois tinha muitas dúvidas para utilizar tecnologias e a internet. (Sandra). 
Podemos notar que a utilização do webfólio foi apreciada por diversos estudantes, pois se tornou uma ferramenta utilizada durante todo o semestre letivo como forma de avaliação contínua que contava com os devidos feedbacks do professor.

O acompanhamento da sua construção e durante as aulas era realizado continuamente e havia momentos para sanar dúvidas e para socializações. Porém, inicialmente alguns estudantes tiveram receio quanto ao trabalho com o webfólio, o que ficou evidenciando em depoimentos, como os transcritos a seguir:

\section{Achava que seria um trabalho bem difícil, pois já tinha ouvido falar, mas não tinha desenvolvido (Sônia). \\ Achava que não iria conseguir desenvolver o meu webfólio. Não tinha muito conhecimento sobre como seria. E também uma coisa nova. (Sérgio). \\ Em um primeiro momento senti um pouco de indisposição, mas logo depois fui tomando gosto pela coisa, foi surgindo a possibilidade de que eu organizasse da minha forma e exercitando a minha criatividade. Depois foi legal! (Sandro).}

O comportamento do estudante ao longo do semestre mudou muito no que se refere ao trabalho com o webfólio. No início observamos certa rejeição e notamos os estudantes temerosos quanto à nova estratégia e ao fato de estarem experimentando algo diferente para serem avaliados. Contudo, iniciaram o trabalho na disciplina lendo e estudando sobre o uso do webfólio e suas possibilidades de organização, o que possibilitou elencarem combinados e algumas fases para o trabalho.

Os estudantes tiveram acesso a aportes teóricos para a construção do webfólio, a partir das ideias de Barberà (2005), que sugere as seguintes etapas:

1. A coleta de evidências - nessa fase os estudantes coletam fotos, imagens, selecionam textos ou partes dos textos estudados, imagens, vídeos, e outros materiais que farão parte do webfólio.

2. A seleção das evidências - aqui o estudante escolhe, dentre os materiais já coletados aqueles que realmente irão fazer parte do webfólio. Começa-se ai a organizar, classificar, selecionar o que está aprendendo. O estudante também nessa fase terá a oportunidade de ver e rever se os conteúdos selecionados condizem com as suas aprendizagens.

3. A reflexão - nessa fase o estudante reflete sobre as evidências de suas aprendizagens que foram selecionadas. Pensa, reflete, identifica, analisa sobre o seu processo de aprendizagem revendo os pontos fortes e o que ainda precisa ser trabalhado para que venha a aprender. É uma oportunidade de criar mecanismos para melhorar o processo de aprendizagem.

4. A publicação - aqui o estudante já organizou e realiza a divulgação das suas evidências de aprendizagens sejam por meio de textos, vídeos, imagens, charges, e outros materiais desde que contenham as reflexões feitas acerca dos conteúdos aprendidos.

Não poderíamos deixar de mencionar que o trabalho com o webfólio teve como tema central a "avaliação da aprendizagem". Nesse sentido, todas as produções giraram em torno desse tema e que também se tratava da disciplina na quais todos estavam matriculados. Cada estudante podia organizar o seu webfólio de forma criativa e livre. Foram postadas atividades 
como: leituras realizadas, mapas conceituais construídos, sínteses desenvolvidas de textos, história da vida estudantil e as marcas da avaliação, imagens, charges, vídeos outros materiais.

A partir da leitura de Lunar (2007), acreditamos que o webfólio é uma possibilidade de avaliação que busca atrelar, à sua construção, características como:

- Formativa - possibilita modificação, ajustes, reflexões durante o processo e possíveis alterações com o objetivo de melhorar a aprendizagem;

- Contínua - implica uma constante construção, reconstrução, envolvimento e não apenas em momentos isolados ou fragmentados no processo avaliativo;

- Integral - abarca os vários elementos do processo de construção de conhecimentos não só relacionados ao cognitivo, mas apresenta outros como o social, afetivo, cultural, ideológico e outras dimensões;

- Individualizada - apresenta as características de cada sujeito, as suas crenças e visões de mundo, possibilitando conhecer o ritmo e os estilos de aprendizagem de cada estudante;

- Qualitativa - baseia-se em critérios de qualidade organizados pelos estudantes e em conformidade com o objetivo do portfólio e privilegia os resultados de forma heterogênea;

- Contextualizada - está inserido em um determinado contexto que apresenta consigo suas marcas e contradições, de acordo com a realidade do estudante ao construir o seu portfólio.

Desse modo, a partir do que foi coletado por meio dos depoimentos dos interlocutores, podemos sinalizar que o trabalho avaliativo por meio do webfólio apresenta:

a) Caráter inovador - pouco trabalhado e conhecido pelos participantes além de não possuírem a vivência e a experiência do trabalho com webfólio na prática avaliativa.

Não conhecia o webfólio. Foi tudo novidade para mim e também desafiadora (Suzana).

b) Capacidade de aprender a aprender - o estudante assumiu uma postura investigativa e protagonista do seu processo de aprendizagens.

Eu fiquei muito feliz ao construir o meu webfólio. Tive que pesquisar muitas coisas como imagens, vídeos e outros materiais para o webfólio ficar legal. Deu vontade de construir em outra disciplina como EJ A (Sandra).

c) A ideia de processo de aprendizagens - cada estudante ia construindo o seu webfólio, à medida que fazia os estudos da disciplina, por meio de textos, pesquisas e outros recursos. As várias aprendizagens iam surgindo sejam essas conceituais, procedimentais ou atitudinais.

Aprendi bastante ao construir o meu webfólio. E também me senti bastante útil quando vi que outras pessoas estavam acessando o meu webfólio. Ai foi que eu comecei a postar mais materiais sobre a avaliação da aprendizagem. Foi gratificante. (Sérgio).

d) Relação entre teoria e prática - os estudantes perceberam toda a relação entre a teoria estudada/refletida e puderam pôr em prática uma concepção de avaliação formativa e participativa por meio da construção do webfólio. 
Foi interessante, porque tudo que discutíamos na disciplina sobre avaliação íamos construindo e fazendo as devidas relações, como por exemplo, os feedback, vivenciar a avaliação formativa. (Sônia).

e) Capacidade de utilizar os recursos das tecnologias da informação e comunicação outro ponto a destacar foi o maior contato com os recursos tecnológicos para a construção do webfólios.

Tive que ir pesquisar na internet. Tive que procurar vários materiais para postar no meu webfólio, ver se ia ser construído como se fosse um blog desde que tivesse relação com a avaliação da aprendizagem. Claro que tudo que eu coloquei foi feita uma reflexão sobre o porquê de postar no webfólio. (Sandro).

Segundo Araújo (2011):

Com o desenvolvimento das tecnologias informacionais e comunicacionais, os portfólios digitais ou eletrônicos ganham espaço em relação aos portfólios organizados em pastas, caixas ou outros aparatos físicos Eles podem estar agregados a um ambiente virtual de aprendizagem ou serem construídos em espaços virtuais gratuitos como blogs e wikis. (ARAUJ O, 2011, p. 176).

f) Exercício do processo de autoria - cada estudante experimentou com autonomia ser protagonista da construção do seu webfólio, vivenciando processos de criatividade, reflexão, autoavaliação e parcerias.

Foi interessante construir o webfólio, pois senti-me valorizada por que outras pessoas iam ver as minhas produções. Tive algumas dificuldades iniciais, mas valeu a pena, pois consegui aprender como organizar o meu webfólio do jeito que eu queria. Claro que dentro do tema que foi a avaliação. (Sara).

Assim, diante de tudo que foi discutido podemos expor uma síntese da pesquisa realizada com o webfólio como possibilidade avaliativa.

a) Aspectos considerados positivos pelos estudantes:

- Aprofundamento dos temas sobre avaliação.

- $\quad$ Oportunidade para construir e reconstruir o webfólio.

- $\quad$ Aprenderam a extrair informações importantes dos textos estudados.

- Utilização de diversas ferramentas tecnológicas.

- $\quad$ Estudo realizado durante todo o semestre sobre o tema da avaliação;

- Integração entre teoria e prática.

- $\quad$ Sistematização das produções feitas na disciplina.

- Aprenderam a relacionar o conteúdo da disciplina com outros temas e a avaliação.

- $\quad$ Acompanhamento de qualquer lugar que se tenha acesso à internet.

b) Aspectos considerados negativos pelos estudantes:

- $\quad$ Falta de costume no exercício da escrita e da reflexão.

- Dúvida sobre o que postar e colocar no webfólio, devido à indecisão.

- A falta de acesso à internet para manter o webfólio atualizado.

- Dúvidas sobre a organização do webfólio. 
- A falta de tempo, pois tínhamos outras disciplinas.

- $\quad$ Ansiedade inicial, diante da novidade do webfólio.

- $\quad$ Pouca vivência com alguns recursos tecnológicos.

- Pouca vivência com processos criativos, fora de "padrões e modelos fixos".

C) Sugestões realizadas pelos estudantes:

- Mais leituras e exposição de outros webfólios.

- Ter maior tempo para socializações durante o processo, porque duas foram poucas.

- Criar subtemas dentro do tema central da avaliação.

- Indicaram que o webfólio pode ser mantido como outra possibilidade de avaliação.

- Criar uma página para colocar todos os webfólios juntos.

Podemos mencionar, ainda, que o trabalho com o webfólio como prática avaliativa foi permeada de sentidos, significados e desafios, tanto para o professor como também para os estudantes. A utilização do webfólio permitiu avaliar de forma compartilhada, participativa e dialógica com todos os envolvidos nos processos de ensino e de aprendizagens.

De acordo com Moreira e Ferreira (2011) a sua utilização:

[...] facilita a avaliação colaborativa ou partilhada, bem como o estabelecimento dos objetivos pessoais, definidos que individualmente que por acordo colaborativo. O portfólio reflexivo é compreendido como instrumento facilitador dos processos de auto e heteroavaliação [...] (MOREIRA; FERREIRA, 2011, p. 65-66).

Assim, compreendemos o quanto o webfólio reflete não apenas nas produções relativas à dimensão cognitiva, no seu sentido restrito, mas também nos aspectos do fazer, do ser e do conviver que perpassam a produção intelectual do sujeito. A proposta do seu uso como procedimento avaliativo chama a atenção por configurar-se, tanto para os estudantes como para os professores, como um novo formato de prática avaliativa, ao qual as atuações docentes e discentes e a organização do trabalho adquirem novas dimensões, com vistas à formação integral dos estudantes, à reflexão e à constante formulação de indagações.

\section{Considerações finais}

Diante das evidências expostas e discutidas neste texto, no que diz respeito ao trabalho com o webfólio ou portfólio online em práticas avaliativas, podemos ratificar a necessidade do rompimento com uma avaliação que exclui e classifica e que não está a serviço das aprendizagens.

Não poderíamos deixar de mencionar que, à luz do diálogo tecido com os teóricos apresentados no decorrer deste trabalho, foi possível percebermos o quanto já avançamos em relação a outras posturas avaliativas e também quanto à utilização das tecnologias da informação e comunicação. Porém, restam-nos ainda alguns desafios, como os já mencionados, 
e outros relativos à construção de práticas avaliativas de fato formativas, participativas, dialógicas e que estejam verdadeiramente a serviço das aprendizagens.

Vale ressaltar que a nossa experiência e a pesquisa desenvolvida possibilitaram-nos algumas reflexões que foram tecidas ao longo deste texto. Esperamos que elas possam provocar outros debates e outras produções, com vistas à construção de conhecimentos para o campo da avaliação das aprendizagens.

As mudanças na organização do trabalho pedagógico e no processo avaliativo não ocorrem de um momento para o outro. É preciso ressignificar crenças e concepções por meio de uma formação teórica e metodologicamente comprometida com a transformação e com a inclusão de todos na sociedade. É necessário, ainda, abertura e disposição para o novo, para a mudança, ousando buscar formas de trabalho que respeitem a singularidade de cada sujeito, bem como o seu ritmo e seu percurso de aprendizagens.

\section{Referências}

ALVES, Leonir Pessate. Portfólios como instrumentos de avaliação dos processos de ensinagem. In: ANASTASIOU, Léa das Graças Camargos e ALVES, Leonir Pessate (Orgs.). Processos de ensinagem na universidade: pressupostos para as estratégias de trabalho em aula. 6.ed. Joinville, SC: UNIVILLE, 2006, p. 101-120.

ALVES, Leonir Pessate. Portfólios como instrumentos de avaliação dos processos de ensinagem. 26a Reunião Anual da ANPED, Poços de Caldas- MG, 5 a 8 de outubro de 2003, p. 1-14.

ARAÚJ O, Ivanildo Amaro de. O Portfólio eletrônico na formação de professores: caleidoscópio de múltiplas vivências, práticas e possibilidades da avaliação formativa. In: VILLAS BOAS, Benigna Maria de Freitas (Org.). Avaliação formativa: práticas inovadoras. Campinas, SP: Papirus, 2001, p. 167-192.

BARBERÀ, Elena, La evaluación de competencias complejas: la práctica del portafolio. Educere, vol 9, núm.31, octubre-diciembre, 2005, p. 497-504.

CANO, Elena. EI portafolios del profesorado universitario: un instrumento para la evaluación y para el desarrollo profesional. Barcelona, España; Ediciones octaedro, S.L., 2005.

ESPINOSA, María Paz Prendes e SÁNCHEZ VERA, María Del Mar. Portafolio eletrônico: posibilidad para los docentes. Pixel-Bit. Revista de Medios y Educación. n.32. Marzo, 2008, p. 21-34.

GONZÁLEZ REY, Fernando L. O Sujeito que aprende; desafios do desenvolvimento do tema da aprendizagem na psicologia e na prática pedagógica. In: TACCA, Maria Carmen V. R.(org.). Aprendizagem e trabalho pedagógico. Campinas, SP: Alínea, 2006.p. 29-44.

GONZÁLEZ REY, Fernando L. O Valor heurístico da subjetividade na investigação psicológica. In: GONZÁLEZ REY, Fernando L. (Org.). Subjetividade, complexidade e pesquisa em Psicologia. São Paulo: Thomson, 2005, p.27-51.

GRILO, João Maria e MACHADO, Constança Gomes. "Portfolios" reflexivos na formação inicial de professores de Biologia e Geologia: viagens na terra do eu. In: SÁ-CHAVES, I dália (org.). Os portfólios reflexivos (também) trazem gente dentro: reflexões em torno do seu uso na humanização dos processos educativos. Portugal: Porto Editora, 2005, p. 22-49.

HADJI, Charles. Avaliação desmistificada. Trad. Patrícia C. Ramos. Porto Alegre: Artmed, 2001.

HERNÁNDEZ, Fernando. Transgressão e mudança na educação: os projetos de trabalho. Trad. Jussara Haubert Rodrigues. Porto Alegre: Artmed, 1998.

HOFFMANN, Jussara. O J ogo do contrário em avaliação. 2. ed.Porto Alegre: Mediação, 2006.

LIBÂNEO, José Carlos. As teorias pedagógicas modernas revisitadas pelo debate contemporâneo na Educação. In: LIBÂNEO, José Carlos e SANTOS, Akiko(Orgs.). Educação na era do conhecimento em rede e transdisciplinaridade. Campinas, SP: Alínea, 2005. p.19-62. 
LUCKESI, Cipriano Carlos. Avaliação da aprendizagem escolar. São Paulo: Cortez, 2002.

LUNAR, Lisette. EI Portafolio: estrategia para evaluar la producción escrita en inglés por parte de estudiantes universitarios. Núcleo 24. 2007, p 63-96.

MARTíNEZ, Albertina Mitjáns. El profesor como sujeto: elemento esencial de la formación de professores para la educación inclusiva. Revista Movimento. n.7, maio, 2003. p.137-149.

MITJÁNS MARTíNEZ, Albertina. A Teoria da subjetividade de González Rey: uma expressão do paradigma da complexidade na Psicologia. In: GONZÁLEZ REY, Fernando L.(Org.). Subjetividade, complexidade e pesquisa em Psicologia. São Paulo: Thomson, 2005, p.01-25.

MOREIRA, Jacinta Rosa; FERREIRA, Maria José. Webfólio reflexivos: contributos para o desenvolvimiento profissional do profesor. Educação, Formação \& Tecnologias. 4, (2), 2011, 61-75.

NUNES, Alexandra e MOREIRA, António. O "Portfolio" na aula de Língua Estrangeira: uma forma de aprender a aprender e a ser (para alunos e professores). In: SÁ-CHAVES, Idália (org.). Os portfólios reflexivos (também) trazem gente dentro: reflexões em torno do seu uso na humanização dos processos educativos. Portugal: Porto Editora, 2005, p. 52-66.

ROMANOWSKI, Joana Paulin. Aprender: uma ação interativa. In: VEIGA, IIma Passos Alencastro (org.). Lições de didática. Campinas, SP: Papirus, 2006, p.101-122.

SÁNCHEZ, Raquel Barragán. El portafolio, metodología de evaluación y aprendizaje de cara al nuevo espacio Europeo de Educación Superior. Una experiencia práctica en la Universidad de Sevilla. Revista Latinoamericana de Tecnología Educativa. Volumen 4, número 1, 2005, p. 121-139.

SHORES, Elizabeth \& GRACE, Cathy. Manual de portfólio: um guia passo a passo para o professor. Trad. Ronaldo Cataldo Costa. Porto Alegre: Artmed, 2001.

VILLAS BOAS, Benigna Maria de Freitas. O Portfólio no curso de Pedagogia: ampliando o diálogo entre professor e aluno. Educação e Sociedade. vol. 26, n.90, jan/abr, Campinas - SP, 2005, p. 291- 306.

VILLAS BOAS, Benigna Maria de Freitas. Portfólio, avaliação e trabalho pedagógico. Campinas, SP: Papirus, 2004. 